\title{
Association between obesity and clinical prognosis in patients infected with SARS- CoV-2
}

Shao-Hang Cai ${ }^{1 *+} \mathbb{D}$, Wei Liao ${ }^{2,3+}$, Shu-Wei Chen ${ }^{3,4}$, Li-Li Liü3,5, Si-Yao Liu ${ }^{6}$ and Zhi-Dan Zheng ${ }^{7 *}$

\begin{abstract}
Background: It is well established that obesity is a disease of sustained low-grade inflammation. However, it is currently unknown if obesity plays a role in the clinical manifestations and prognosis of severe acute respiratory syndrome coronavirus 2 (SARS-CoV-2) infected patients. In this study, we aimed to investigate whether obesity played a role in clinical manifestations and prognosis in patients infected with SARS-CoV-2.
\end{abstract}

Methods: This is a retrospective multicenter clinical study. A total of 96 patients hospitalized with SARS-CoV-2 infection were enrolled from Dongguan People's Hospital, Nanfang hospital and the First Affiliated Hospital of Xiamen University between 23 January and 14 February 2020. Demographic and clinical data were extracted from medical records. Acute respiratory distress syndrome (ARDS) was defined as oxygenation index $\left(\mathrm{PaO}_{2} / \mathrm{FiO}_{2}\right) \leq 300$ $\mathrm{mmHg}$. We grouped patients through the body mass index (BMI). Associations were examined using the $t$ test, $x^{2}$ test and multivariate logistic forward regression test.

Results: Patients with $\mathrm{BMI}<24$ were significantly younger $(P=0.025)$ with lower creatine kinase $(P=0.013)$, lower diastolic pressure blood $(P=0.035)$, lower serum creatinine $(P=0.012)$, lower lactate dehydrogenase $(P=0.001)$ and higher platelet count $(P=0.002)$. The BMl level was $20.78 \pm 3.15$ in patients without pneumonia compared with the patients with pneumonia $(23.81 \pm 3.49, P=0.001)$. For patients without ARDS, an average BMl level of $22.65 \pm 3.53$ was observed, significantly lower than patients with ARDS $(24.57 \pm 3.59, P=0.022)$. The mean BMI was $22.35 \pm 3.56$ in patients experienced with relieving the clinical symptoms or stable condition by radiographic tests, lower than patients with disease exacerbation with $24.89 \pm 3.17(P=0.001)$. In addition, lymphocyte count $(r=-0.23, P=0.027)$ and platelet count $(r=-0.44, P<0.001)$ were negatively correlated with BMI. While hemoglobin $(r=0.267, P=$ 0.008), creatine kinase $(r=0.331, P=0.001)$, serum creatinine $(r=0.424, P<0.001)$ and lactate dehydrogenase $(r=$ $0.343, P=0.001)$ were significantly positive correlated with BMI. Multivariate analysis showed that older age $(O R=$ 1.046, $P=0.009)$ and $\mathrm{BMI} \geq 24(O R=1.258, P=0.005)$ were independent risk factors associated ICU admission while $\mathrm{BMI} \geq 24(\mathrm{OR}=4.219, P=0.007)$ was independent risk factor associated with radiographic disease exacerbation.

\footnotetext{
*Correspondence: shaohangcai@foxmail.com; 385338012@qq.com

†Shao-Hang Cai and Wei Liao contributed equally to this work.

'Department of Infectious Diseases and Hepatology Unit, Nanfang Hospital,

Southern Medical University, Guangzhou, Guangdong Province, China

${ }^{7}$ Department of Infectious Diseases, Dongguan people's Hospital, Southern

Medical University, Dongguan, Guangdong Province, China

Full list of author information is available at the end of the article
}

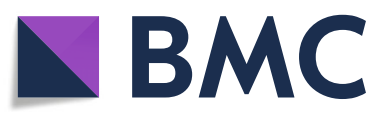

(c) The Author(s). 2020 Open Access This article is licensed under a Creative Commons Attribution 4.0 International License, which permits use, sharing, adaptation, distribution and reproduction in any medium or format, as long as you give appropriate credit to the original author(s) and the source, provide a link to the Creative Commons licence, and indicate if changes were made. The images or other third party material in this article are included in the article's Creative Commons licence, unless indicated otherwise in a credit line to the material. If material is not included in the article's Creative Commons licence and your intended use is not permitted by statutory regulation or exceeds the permitted use, you will need to obtain permission directly from the copyright holder. To view a copy of this licence, visit http://creativecommons.org/licenses/by/4.0/ The Creative Commons Public Domain Dedication waiver (http://creativecommons.org/publicdomain/zero/1.0/) applies to the data made available in this article, unless otherwise stated in a credit line to the data. 
(Continued from previous page)

Conclusions: Our study found BMI was significantly associated with clinical manifestations and prognosis of patients with SARS-CoV-2 infection. For patients with increased risk, clinicians should intervene promptly to avoid disease progression.

Keywords: SARS-CoV-2, Obesity, Body mass index, Prognosis, Pneumonia, Acute respiratory distress syndrome

\section{Background}

A series of unexplained viral pneumonia cases occurred worldwide recently [1]. Subsequent studies have shown that this series of pneumonia was associated with a new coronavirus infection (SARS-CoV-2) [1, 2]. This virus epidemic is posing a huge threat to global public health [3-5].

This sudden infectious disease is mainly manifested as fever, fatigue, and cough $[6,7]$. Upper respiratory symptoms are relatively rare, which may be due to the fact that the virus infects cells through angiotensin converting enzyme 2, which is mainly expressed in cells of the lower respiratory tract $[8,9]$. About one-half of the patients developed dyspnoea after 1 week [6]. In severe and critical cases, it progressed rapidly (average 9 days) to acute respiratory distress syndrome (ARDS) with only mild symptoms in early stage $[6,10]$. This brings difficulties in managing the infectious diseases. In order to control the epidemic better and reduce the spread of the disease, early detection, quarantine and timely treatment are the keys to management. However, it is still no very clear which cohort of the population is at high risk.

Obesity is now a global health issue $[11,12]$. It is well established that obesity is a disease of sustained low-grade inflammation $[13,14]$. Such inflammation has been suggested to be associated with obesity related disease. A series of inflammatory markers have been proved related with both obesity and obesity associated disease. Previous research has confirmed a positive association between obesity and C-reactive protein level [15]. Similar associations have also been reported for erythrocyte sedimentation rate [16] and some other inflammatory cytokines [17, 18]. Those findings further support the potential association between obesity and inflammation. The interactions between obesity and infectious diseases have recently received increasing recognition. Previously published data have indicated an association between obesity and poor outcome in pandemic H1N1 influenza infection [19]. Obesity is an established risk factor for surgical-site infections, nosocomial infections, periodontitis and skin infections [20]. However, it is currently unknown if obesity plays a role in the clinical manifestations and prognosis of SARS-CoV-2 infected patients.

In this study, the clinical manifestations and clinical outcomes of SARS-CoV-2 infected patients were evaluated. The purpose of this study was to determine the role of obesity in the prognoses of patients infected with SARS-CoV-2.

\section{Subjects and methods \\ Subjects}

This is a retrospective multicentre clinical study. This study was approved by the institutional ethics board of Nanfang Hospital, Southern Medical University. All consecutive patients with confirmed SARS-CoV-2 infection in Dongguan People's Hospital, Nanfang hospital affiliated Southern Medical University and the First Affiliated Hospital of Xiamen University between 23 January and 14 February 2020 were enrolled. Oral consent was obtained from patients. All patients were diagnosed with SARS-CoV-2 by pharyngeal swab samples. The SARSCoV-2 infection diagnostic standard is detection of two target genes of SARS-CoV-2 in pharyngeal swab samples using polymerase chain reaction (PCR) [10].

\section{Data collection}

We collected patient medical records and recorded patient demographic and clinical data. All data were reviewed by a team of experienced physicians. ARDS was defined as acute onset, oxygenation index $\left(\mathrm{PaO}_{2} /\right.$ $\left.\mathrm{FiO}_{2}\right) \leq 300 \mathrm{mmHg}$, and a chest radiograph that showed patchy shadows [21]. We categorized patients based on body mass index (BMI, $\left.\mathrm{kg} / \mathrm{m}^{2}\right)$. All BMIs were calculated based on the height and weight measured on admission.

\section{Statistical analysis}

Continuous variables were expressed as average values and compared with student $t$-test. The categorical variables were expressed as a number (percentage) and compared by chi-square test. A univariate and multivariate regression analysis was used, with the results presented as an odds ratio $(O R)$ with a $95 \%$ confidence interval $(C I)$. All analyses were performed using SPSS software package (version 13.0, SPSS Inc. Chicago, USA), alpha level was 0.05 .

\section{Results}

Characteristics of patients infected SARS-CoV-2 grouped by BMI

A total of 96 patients infected with SARS-CoV-2 were enrolled. Among these, 59 had a BMI $<24$ and 37 of 
them had a BMI $\geq 24$. Demographic and clinical characteristics were compared and shown in Table 1. Patients with $\mathrm{BMI}<24$ were significantly younger than others $(P=0.025)$, while the creatine kinase $(\mathrm{CK})(P=0.013)$, diastolic pressure blood (DBP), serum creatinine $(P=$ $0.012)$ and lactate dehydrogenase $(\mathrm{LDH})(P=0.001)$ level were significantly lower. Platelet counts $(P=0.002)$ were significantly higher in patients with $\mathrm{BMI}<24$.

We also analyzed the difference of clinical characteristics between patients with age $<18$ and $\geq 18$ years old. We found that patients younger than 18 years $(n=15)$ had lower systolic blood pressure (SBP) and DBP than adults $(n=81)$ (SBP: $114.67 \pm 12.98$ vs $127.01 \pm 15.62$ $\mathrm{mmHg}, \quad P=0.011 ; \quad$ DBP: $75.25 \pm 8.52$ vs $84.02 \pm 9.73$ $\mathrm{mmHg}, P=0.004)$. The average level of lymphocyte count in patients younger than 18 years was $2.29 \pm 1.63$, which was significantly higher than that of $\geq 18$-year age group $(1.18 \pm 0.56, P<0.001)$. However, no significantly different with $\mathrm{CK}$ level and lactate level was found between the two groups.

\section{Association between BMI and clinical outcomes of SARS- CoV-2 infected patients}

To further evaluate the association between BMI and the clinical outcomes of SARS-CoV-2 infected patients, we measured the proportion of patients with different outcomes (see Table 2). Among 96 patients infected with SARS-CoV-2, 21 of them were without pneumonia based on the finding of computerized tomography (CT)

Table 1 The demographics and clinical characteristics between patients with COVID-19

\begin{tabular}{|c|c|c|c|}
\hline \multirow[t]{2}{*}{ Characteristic } & \multicolumn{2}{|l|}{ Group } & \multirow{2}{*}{$\begin{array}{l}P \\
\text { value }\end{array}$} \\
\hline & $\mathrm{BMI}<24$ & $\mathrm{BMI} \geq 24$ & \\
\hline Sample size, $n$ & 59 & 37 & - \\
\hline Sex (male), $n(\%)$ & $31(52.5)$ & $23(62.2)$ & 0.355 \\
\hline Age (years) & $35.41 \pm 18.45$ & $44.00 \pm 17.23$ & 0.025 \\
\hline Systolic blood pressure & $124.84 \pm 16.11$ & $126.29 \pm 15.51$ & 0.666 \\
\hline Diastolic blood pressure & $81.13 \pm 9.61$ & $85.57 \pm 10.08$ & 0.035 \\
\hline Creatine kinase & $84.04 \pm 112.12$ & $169.37 \pm 212.25$ & 0.013 \\
\hline Serum lactic acid & $1.64 \pm 0.70$ & $1.39 \pm 0.65$ & 0.123 \\
\hline Neutrophil count & $3.33 \pm 1.50$ & $3.31 \pm 1.41$ & 0.927 \\
\hline Lymphocyte count & $1.46 \pm 1.04$ & $1.19 \pm 0.61$ & 0.169 \\
\hline Hemoglobin & $139.22 \pm 15.07$ & $142.51 \pm 19.95$ & 0.361 \\
\hline Platelet count & $222.23 \pm 66.42$ & $180.89 \pm 51.92$ & 0.002 \\
\hline Serum creatinine & $60.58 \pm 19.09$ & $70.19 \pm 15.18$ & 0.012 \\
\hline $\mathrm{ALT}$ & $20.38 \pm 16.65$ & $26.22 \pm 18.51$ & 0.118 \\
\hline AST & $21.70 \pm 8.59$ & $26.05 \pm 13.88$ & 0.065 \\
\hline Lactate dehydrogenase & $177.82 \pm 54.39$ & $221.94 \pm 73.21$ & 0.001 \\
\hline Smoking tobacco, $n(\%)$ & $5(8.5)$ & $3(8.1)$ & 0.950 \\
\hline
\end{tabular}

ALT Alanine aminotransferase; AST Aspartate aminotransferase
Table 2 Proportion of viral pneumonia by groups

\begin{tabular}{|c|c|c|c|}
\hline \multirow[t]{2}{*}{ Variable } & \multicolumn{2}{|c|}{ Patients with COVID-19 } & \multirow{2}{*}{$\begin{array}{l}\boldsymbol{P} \\
\text { value }\end{array}$} \\
\hline & $\begin{array}{l}\text { Without pneumonia } \\
n=21, n(\%)\end{array}$ & $\begin{array}{l}\text { With pneumonia } \\
n=75, n(\%)\end{array}$ & \\
\hline BMl stage & & & 0.027 \\
\hline$<24$ & $18(85.7)$ & $41(54.7)$ & \\
\hline $24-27.9$ & $3(14.3)$ & $24(32.0)$ & \\
\hline$\geq 28$ & $0(0)$ & $10(13.3)$ & \\
\hline BMI level & $20.78 \pm 3.15$ & $23.81 \pm 3.49$ & 0.001 \\
\hline
\end{tabular}

scan, while 75 patients were diagnosed with pneumonia. The proportions of patients with negative CT results were $85.7,14.3$ and $0 \%$ for patients with $\mathrm{BMI}<24,24-$ 27.9 and $\geq 28$, respectively; however, in pneumonia group, the proportions were $54.7,32.0$ and $13.3 \%$ in respective BMI groups $(P=0.027)$. Mean BMI value was $20.78 \pm 3.15$ in patients without pneumonia, compared with $23.81 \pm 3.49$ with pneumonia $(P=0.001)$.

Among the whole cohort, 25 patients were diagnosed with ARDS. The proportions of patients with ARDS with a $\mathrm{BMI}<24,24-27.9$, and $\geq 28$ were 52.0, 24.0, and $24.0 \%$, respectively, which were significantly different from the proportions of $64.8,29.6$ and $5.6 \%$ in patients without ARDS $(P=0.035)$. Average BMI was $22.65 \pm$ 3.53 in patients without ARDS, which was significantly lower than that of patients with ARDS $(24.57 \pm 3.59, P=$ 0.022, Table 3).

Patients enrolled were received at least one repeat CT scan within 1 month. After treatment, 66 patients showed improved or stable disease, while 30 showed exacerbated disease. The mean BMI was $22.35 \pm 3.56$ in patients with disease stable or relief, which was lower than the mean BMI of $24.89 \pm 3.17$, present in patients with disease exacerbation $(P=0.001)$, as shown in Table 4.

\section{Correlation between BMI and clinical variables}

Interestingly, we found several unexpected clinical variables that were significantly correlated with BMI in all enrolled SARS-CoV-2 infected patients (Fig. 1). Lymphocyte count $(\mathrm{r}=-0.23, P=0.027)$ and platelet count $(\mathrm{r}=-0.44, P<0.001)$ were negatively correlated

Table 3 Proportion of ARDS by groups

\begin{tabular}{llll}
\hline Variable & \multicolumn{2}{l}{ Patients with COVID-19 } & \multirow{P}{P}{} \\
\cline { 2 - 3 } & $\begin{array}{l}\text { Without ARDS } \\
n=71, n(\%)\end{array}$ & $\begin{array}{l}\text { With ARDS } \\
n=25, n(\%)\end{array}$ & \\
\hline BMl stage & & & 0.035 \\
$<24$ & $46(64.8)$ & $13(52.0)$ & \\
$24-27.9$ & $21(29.6)$ & $6(24.0)$ & \\
$\geq 28$ & $4(5.6)$ & $6(24.0)$ & \\
BMl level & $22.65 \pm 3.53$ & $24.57 \pm 3.59$ & 0.022 \\
\hline
\end{tabular}


Table 4 Proportion of clinical outcome by groups

\begin{tabular}{|c|c|c|c|}
\hline \multirow[t]{2}{*}{ Variables } & \multicolumn{2}{|c|}{ COVID-19 patients with disease } & \multirow{2}{*}{$\begin{array}{l}P \\
\text { value }\end{array}$} \\
\hline & $\begin{array}{l}\text { Stable-relieve } \\
n=66, n(\%)\end{array}$ & $\begin{array}{l}\text { Exacerbation } \\
n=30, n(\%)\end{array}$ & \\
\hline BMl stage & & & 0.001 \\
\hline$<24$ & $49(74.2)$ & $10(33.3)$ & \\
\hline $24-27.9$ & $13(19.7)$ & $14(46.7)$ & \\
\hline$\geq 28$ & $4(6.1)$ & $6(20.0)$ & \\
\hline BMI level & $22.35 \pm 3.56$ & $24.89 \pm 3.17$ & 0.001 \\
\hline
\end{tabular}

with BMI, while haemoglobin $(\mathrm{r}=0.267, P=0.008)$, CK $(\mathrm{r}=0.331, P=0.001)$, serum creatinine $(\mathrm{r}=0.424, P<$ $0.001)$, and LDH $(r=0.343, P=0.001)$ were significantly positive correlated with BMI.

\section{Univariate and multivariate analysis of factors associated} with ICU admission

Logistic regression was performed to identify factors that were significantly associated with ICU admission in SARS-CoV-2-infected patients. The results of this multivariate analysis indicated that older age $(O R=1.046, P=$ $0.009)$ and $B M I \geq 24 \quad(O R=1.258, \quad P=0.005)$ were independent risk factors associated with ICU admission among patients with SARS-CoV-2 infection (Table 5).
Univariate and multivariate analysis of factors associated with radiographic disease exacerbation

We also conducted logistic regression to identify factors that were associated with radiographic disease exacerbation in SARS-CoV-2 infected patients. Multivariate analyses showed that $\mathrm{BMI} \geq 24 \quad(O R=4.219, P=0.007)$ was independent risk factors associated with SARS-CoV2 infected patients who experienced radiographic disease exacerbation (Table 6).

\section{Discussion}

In this study, we found that obesity played an important role in development of COVID-19. SARS-CoV-2 infected patients with a higher BMI were more likely to develop ARDS and to experience exacerbated disease. Moreover, we found that patients with higher BMIs had lower lymphocyte counts, lower platelet counts, and higher levels of haemoglobin, CK, creatinine, and LDH. Our results may help to stratify patients with SARSCoV-2 infection: patients with high BMIs should receive prompt intervention to avoid disease progression. Most patients with SARS-CoV-2 infection will develop pneumonia [22]. However, a small number of patients have negative imaging findings for unclear reasons. As we know, the largest study to-date indicated that 3498 of the 3665 (95.5\%) confirmed cases were diagnosed with

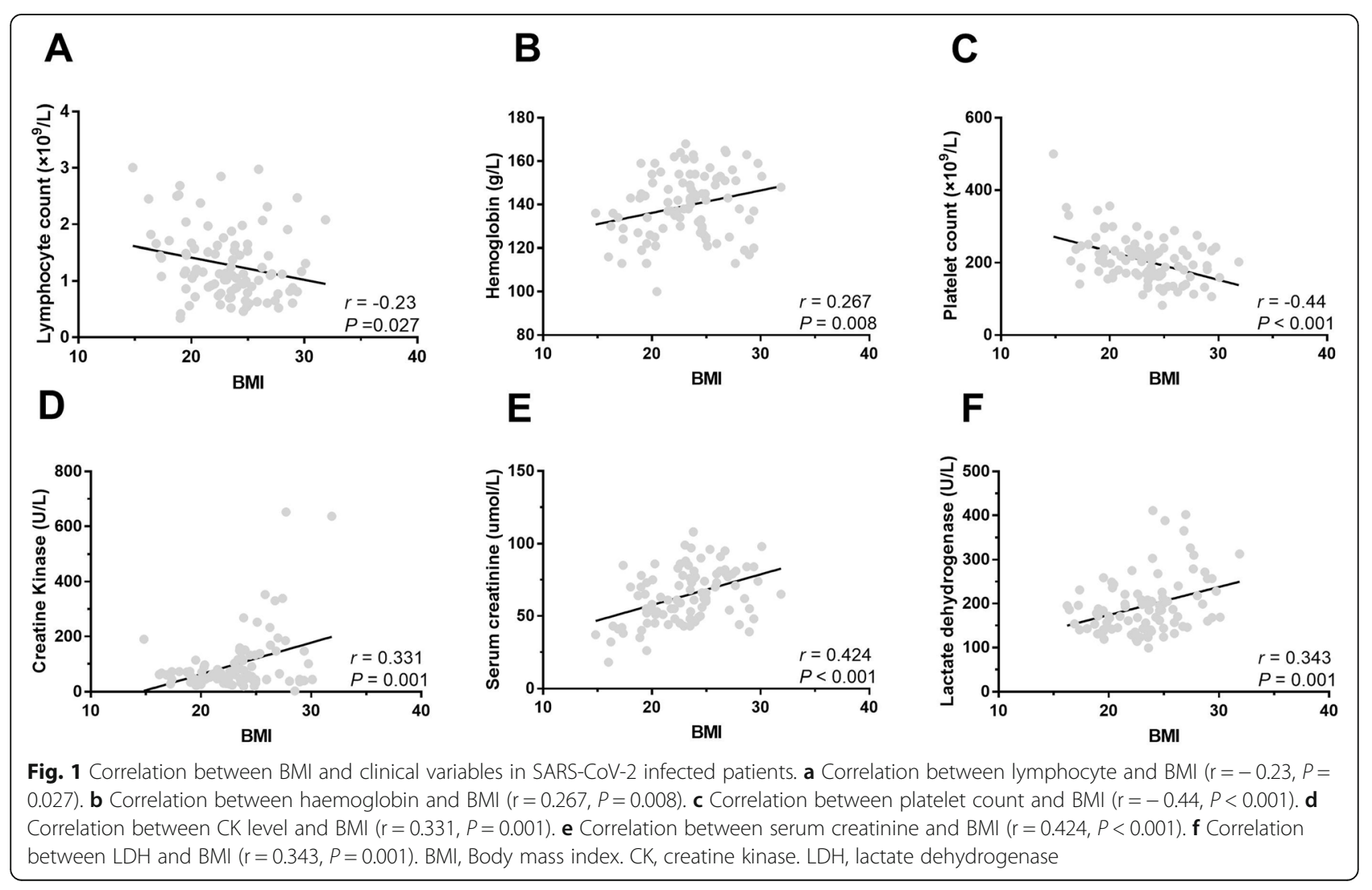


Table 5 Factors associated with ICU admission

\begin{tabular}{|c|c|c|c|c|c|c|}
\hline \multirow[t]{2}{*}{ Variables } & \multicolumn{3}{|c|}{ Univariate analysis } & \multicolumn{3}{|c|}{ Multivariate analysis } \\
\hline & $\overline{O R}$ & $95 \% \mathrm{Cl}$ & $\boldsymbol{P}$ value & $\overline{O R}$ & $95 \% \mathrm{Cl}$ & $\boldsymbol{P}$ value \\
\hline Sex (male vs female) & 1.361 & $0.595-3.112$ & 0.465 & & & \\
\hline Age & 1.043 & $1.017-1.070$ & 0.001 & 1.046 & $1.011-1.081$ & 0.009 \\
\hline Systolic blood pressure & 1.026 & $0.998-1.055$ & 0.065 & & & \\
\hline Diastolic blood pressure & 1.023 & $0.980-1.068$ & 0.295 & & & \\
\hline Creatine kinase & 1.002 & $0.999-1.004$ & 0.256 & & & \\
\hline Serum lactic acid & 0.956 & $0.496-1.843$ & 0.894 & & & \\
\hline Neutrophil count & 0.919 & $0.689-1.227$ & 0.569 & & & \\
\hline Lymphocyte count & 0.532 & $0.274-1.032$ & 0.062 & & & \\
\hline Hemoglobin & 1.016 & $0.992-1.040$ & 0.198 & & & \\
\hline Platelet count & 0.992 & $0.985-1.000$ & 0.041 & & & \\
\hline Serum creatinine & 1.021 & $0.998-1.045$ & 0.073 & & & \\
\hline $\mathrm{ALT}$ & 1.019 & $0.995-1.044$ & 0.117 & & & \\
\hline AST & 1.042 & $1.002-1.084$ & 0.042 & & & \\
\hline Lactate dehydrogenase & 1.009 & $1.002-1.016$ & 0.016 & & & \\
\hline Smoking tobacco (yes vs no) & 1.041 & $0.234-4.630$ & 0.958 & & & \\
\hline BMI level (< 24 vs $\geq 24)$ & 5.190 & $2.110-12.763$ & $<0.001$ & 1.258 & $1.071-1.478$ & 0.005 \\
\hline
\end{tabular}

OR Odds ratio; Cl Confidence interval; ALT Alanine aminotransferase; AST Aspartate aminotransferase

pneumonia [23]. According to the 2019 New Coronavirus Pneumonia Diagnosis and Treatment Plan recommended by the National Health Committee of China, these patients without pneumonia showed only low fever and mild fatigue, and usually recovered after 1 week.
Our research confirmed that, although SARS-CoV-2 infection was confirmed, some patients had negative CT results. In addition, our study found that this situation was more likely to occur in young patients with lower BMIs. Although the prognosis of these patients seems to

Table 6 Factors associated with radiographic exacerbation

\begin{tabular}{|c|c|c|c|c|c|c|}
\hline \multirow[t]{2}{*}{ Variables } & \multicolumn{3}{|c|}{ Univariate analysis } & \multicolumn{3}{|c|}{ Multivariate analysis } \\
\hline & $\overline{O R}$ & $95 \% \mathrm{Cl}$ & $\boldsymbol{P}$ value & $\overline{O R}$ & $95 \% \mathrm{Cl}$ & $\boldsymbol{P}$ value \\
\hline Sex (male vs female) & 1.025 & $0.429-2.448$ & 0.956 & & & \\
\hline Age & 1.023 & $0.998-1.048$ & 0.069 & & & \\
\hline Systolic blood pressure & 1.009 & $0.982-1.038$ & 0.513 & & & \\
\hline Diastolic blood pressure & 1.001 & $0.958-1.045$ & 0.978 & & & \\
\hline Creatine kinase & 1.002 & $1.000-1.005$ & 0.097 & & & \\
\hline Serum lactic acid & 1.041 & $0.523-2.074$ & 0.909 & & & \\
\hline Neutrophil count & 0.979 & $0.725-1.322$ & 0.889 & & & \\
\hline Lymphocyte count & 0.684 & $0.350-1.338$ & 0.267 & & & \\
\hline Hemoglobin & 1.006 & $0.981-1.032$ & 0.630 & & & \\
\hline Platelet count & 0.997 & $0.990-1.004$ & 0.398 & & & \\
\hline Serum creatinine & 1.008 & $0.984-1.033$ & 0.503 & & & \\
\hline ALT & 1.017 & $0.992-1.042$ & 0.190 & & & \\
\hline AST & 1.025 & $0.986-1.065$ & 0.208 & & & \\
\hline Lactate dehydrogenase & 1.001 & $0.994-1.008$ & 0.756 & & & \\
\hline Smoking tobacco (yes vs no) & 1.356 & $0.302-6.083$ & 0.691 & & & \\
\hline BMI level (< 24 vs $\geq 24)$ & 5.765 & $2.255-14.734$ & $<0.001$ & 4.219 & $1.490-11.944$ & 0.007 \\
\hline
\end{tabular}


be better than older patients with high BMIs, repeated CT examinations are still needed, particularly if the clinical symptoms worsen.

Obesity is a common worldwide epidemic. Obesity is usually accompanied by a low-grade chronic inflammatory state, which is characterized by an increase in systemic inflammation markers $[13,16]$. This mild chronic inflammation and non-specific activation of the immune system are thought to induce obesity-related diseases [13]. The reasons why obesity causes inflammation have not yet been well described, but studies have revealed that adipocytes secrete a variety of cytokines that help initiate an inflammatory response $[24,25]$. In long-term chronic inflammation, a series of changes occur in the body, including in blood glucose, lipid, and hormone levels [24]. These changes are accompanied by insulin and catecholamine resistance, abnormal tissue remodelling and fibrosis [24]. Some patients with SARS-CoV-2 infections rapidly developed into critically ill patients, in which case the disease usually manifests as ARDS [6, 26]. Current research showed that the mortality rate of SARS-CoV-2 infected patients was $4-15 \%[6,26]$. It is therefore important to identify this population early. However, the subpopulations who became severely ill may have had moderate to low fever during the early course of the disease, and these patients are still difficult to screen. Whether obesity plays a role here is unknown, and further researches are still needed.

Our results suggest high BMI is closely related to patient disease progression. At the same time, our study showed that BMI was negatively correlated with lymphocytes and platelets, but positively correlated with CK, $\mathrm{LDH}$, and creatinine. Patients with SARS-CoV-2-infections often experience lymphocytopenia [4, 7]. It is unknown whether SARS-CoV-2 infection will induce immune deficiency, and whether obesity and adipocytes play a role here. However, according to the results of our study, patients who with a high BMI, even if their symptoms are not obvious, should be given sufficient attention to avoid rapid deterioration.

The current study has several limitations. Firstly, this was a retrospective survey, with a relatively limited sample size. In addition, the role of obesity in the pathophysiology of SARS-CoV-2 infection requires further research to confirm. It is also an important topic to identify patients with SARS-CoV-2-associated pneumonia developing ARDS during the course of disease. This issue merits additional research.

\section{Conclusions}

Our study found that BMI was significantly related with clinical manifestations and clinical outcomes of patients with SARS-CoV-2 infections. Patients with higher BMIs were more likely to develop ARDS and to experience disease progression. Older age and high BMI are independent risk factors associated with ICU admission in SARS-CoV-2 infected patients, while patients with higher BMIa are more likely to experience disease exacerbation. For patients with risk factors, clinicians should intervene promptly to avoid disease progression.

\begin{abstract}
Abbreviations
ARDS: Acute respiratory distress syndrome; BMI: Body mass index; OR: Odds ratio; Cl: Confidence interval; CK: Creatine kinase; DBP: Diastolic pressure blood; SBP: Systolic blood pressure; CT: Computerized tomography; COVID19: Corona Virus Induced Disease 2019
\end{abstract}

\section{Acknowledgements}

We wish to thank Jian Zhang for his helpful assistance in the study.

\section{Authors' contributions}

Shaohang Cai, Lili Liu, Wei Liao designed and guided this study, Shuwen Chen and Shaohang Cai wrote the main manuscript text. Zhidan Zheng and Siyao Liu prepared all tables and data analysis. All authors reviewed the manuscript. The author(s) read and approved the final manuscript.

\section{Funding}

This work was supported by the grants from the Major Science and Technology Special Project of China (2017ZX09304016,

2017ZX10302201004008), the National Natural Science Foundation of China (81971949) and the Clinical Research Startup Program of Southern Medical University by High-level University Construction Funding of Guangdong Provincial Department of Education (LC2016PY003).

\section{Availability of data and materials}

Authors can confirm all relevant data are included in the article and materials are available on request from the authors. The original data of this study has been uploaded to the RDD platform (RDDA2020001502).

\section{Ethics approval and consent to participate}

The Institutional Review Board of Nanfang Hospital, Southern Medical University had approved this study. All procedures followed were in accordance with the ethical standards of the responsible committee on human experimentation and with the Helsinki Declaration of 1975, as revised in 2008. Oral consent was obtained from patients.

\section{Consent for publication}

Not applicable.

\section{Competing interests}

The authors declare that they have no financial or non-financial interests with other people or organizations that could inappropriately influence this work.

\section{Author details}

'Department of Infectious Diseases and Hepatology Unit, Nanfang Hospital, Southern Medical University, Guangzhou, Guangdong Province, China. ${ }^{2}$ Intensive Care Unit, Sun Yat-sen University Cancer Center, Guangzhou, Guangdong Province, China. ${ }^{3}$ Collaborative Innovation Center of Cancer Medicine, Guangzhou, Guangdong Province, China. ${ }^{4}$ Department of Head and Neck Surgery, Sun Yat-sen University Cancer Center, Guangzhou, Guangdong Province, China. ${ }^{5}$ Department of Pathology, Sun Yat-sen University Cancer Center, Guangzhou, Guangdong Province, China. ${ }^{6}$ Emergency Department, First Affiliated Hospital of Xiamen University, Xiamen, Fujian province, China. 'Department of Infectious Diseases, Dongguan people's Hospital, Southern Medical University, Dongguan, Guangdong Province, China. 
Received: 3 March 2020 Accepted: 16 June 2020

Published online: 29 June 2020

\section{References}

1. Zhu N, Zhang D, Wang W, Li X, Yang B, Song J, et al. A novel coronavirus from patients with pneumonia in China, 2019. N Engl J Med. 2020;382(8): 727-33.

2. $X u X W, W u X X$, Jiang $X G, X u K J$, Ying $L J, M a C L$, et al. Clinical findings in a group of patients infected with the 2019 novel coronavirus (SARS-Cov-2) outside of Wuhan, China: retrospective case series. BMJ. 2020;368:m606.

3. Holshue ML, DeBolt C, Lindquist S, Lofy KH, Wiesman J, Bruce H, et al. First case of 2019 novel coronavirus in the United States. N Engl J Med. 2020; 382(10):929-36.

4. Parry J. China coronavirus: cases surge as official admits human to human transmission. BMJ. 2020;368:m236.

5. Silverstein WK, Stroud L, Cleghorn GE, Leis JA. First imported case of 2019 novel coronavirus in Canada, presenting as mild pneumonia. Lancet. 2020; 395(10225):734.

6. Huang C, Wang Y, Li X, Ren L, Zhao J, Hu Y, et al. Clinical features of patients infected with 2019 novel coronavirus in Wuhan, China. Lancet. 2020;395(10223):497-506.

7. Zhang JJ, Dong X, Cao YY, Yuan YD, Yang YB, Yan YQ, et al. Clinical characteristics of 140 patients infected by SARS-CoV-2 in Wuhan, China. Allergy. 2020;https://doi.org/10.1111/all.14238.

8. Ren X, Glende J, Al-Falah M, de Vries V, Schwegmann-Wessels C, Qu X, et al. Analysis of ACE2 in polarized epithelial cells: surface expression and function as receptor for severe acute respiratory syndrome-associated coronavirus. J Gen Virol. 2006;87(Pt 6):1691-5.

9. Zhou P, Yang XL, Wang XG, Hu B, Zhang L, Zhang W, et al. A pneumonia outbreak associated with a new coronavirus of probable bat origin. Nature. 2020:579:270-3.

10. Jin $Y H$, Cai $L$, Cheng $Z S$, Cheng $H$, Deng $T$, Fan $Y P$, et al. A rapid advice guideline for the diagnosis and treatment of 2019 novel coronavirus (2019nCoV) infected pneumonia (standard version). Mil Med Res. 2020;7(1):4.

11. Ryan DH, Kahan S. Guideline recommendations for obesity management. Med Clin North Am. 2018;102(1):49-63.

12. Ou H, Cai S, Liu Y, Xia M, Peng J. A noninvasive diagnostic model to assess nonalcoholic hepatic steatosis in patients with chronic hepatitis B. Ther Adv Gastroenterol. 2017;10(2):207-17.

13. Cox AJ, West NP, Cripps AW. Obesity, inflammation, and the gut microbiota. Lancet Diabetes Endocrinol. 2015;3(3):207-15.

14. Cai $S, O u$ Z, Liu D, Liu L, Liu Y, Wu X, et al. Risk factors associated with liver steatosis and fibrosis in chronic hepatitis $B$ patient with component of metabolic syndrome. United European Gastroenterol J. 2018;6(4):558-66.

15. Choi J, Joseph L, Pilote L. Obesity and C-reactive protein in various populations: a systematic review and meta-analysis. Obes Rev. 2013;14(3): 232-44

16. de Rooij SR, Nijpels G, Nilsson PM, Nolan JJ, Gabriel R, Bobbioni-Harsch E, et al. Low-grade chronic inflammation in the relationship between insulin sensitivity and cardiovascular disease (RISC) population: associations with insulin resistance and cardiometabolic risk profile. Diabetes Care. 2009;32(7): 1295-301.

17. Bahceci M, Gokalp D, Bahceci S, Tuzcu A, Atmaca S, Arikan S. The correlation between adiposity and adiponectin, tumor necrosis factor alpha, interleukin6 and high sensitivity C-reactive protein levels. Is adipocyte size associated with inflammation in adults? J Endocrinol Investig. 2007;30(3):210-4

18. Marques MA, Combes M, Roussel B, Vidal-Dupont L, Thalamas C, Lafontan $M$, et al. Impact of a mechanical massage on gene expression profile and lipid mobilization in female gluteofemoral adipose tissue. Obes Facts. 2011; 4(2):121-9.

19. Tsatsanis C, Margioris AN, Kontoyiannis DP. Association between H1N infection severity and obesity-adiponectin as a potential etiologic factor. J Infect Dis. 2010;202(3):459-60.

20. Huttunen R, Syrjanen J. Obesity and the risk and outcome of infection. Int J Obes. 2013;37(3):333-40.

21. Ranieri VM, Rubenfeld GD, Thompson BT, Ferguson ND, Caldwell E, Fan E, et al. Acute respiratory distress syndrome: the Berlin definition. JAMA. 2012; 307(23):2526-33.

22. Zu ZY, Jiang MD, Xu PP, Chen W, Ni QQ, Lu GM, et al. Coronavirus disease 2019 (COVID-19): a perspective from China. Radiology. 2020:200490. https:// doi.org/10.1148/radiol.2020200490.
23. Yang Y, Lu Q, Liu M, Wang Y, Zhang A, Jalali N, et al. Epidemiological and clinical features of the 2019 novel coronavirus outbreak in China. medRxiv. 2020. https://doi.org/10.1101/2020.02.10.20021675.

24. Karczewski J, Sledzinska E, Baturo A, Jonczyk I, Maleszko A, Samborski P, et al. Obesity and inflammation. Eur Cytokine Netw. 2018;29(3):83-94.

25. Reilly SM, Saltiel AR. Adapting to obesity with adipose tissue inflammation. Nat Rev Endocrinol. 2017:13(11):633-43.

26. Wang D, Hu B, Hu C, Zhu F, Liu X, Zhang J, et al. Clinical characteristics of 138 hospitalized patients with 2019 novel coronavirus-infected pneumonia in Wuhan, China. JAMA. 2020;323(11):1061-9.
Ready to submit your research? Choose BMC and benefit from:

- fast, convenient online submission

- thorough peer review by experienced researchers in your field

- rapid publication on acceptance

- support for research data, including large and complex data types

- gold Open Access which fosters wider collaboration and increased citations

- maximum visibility for your research: over $100 \mathrm{M}$ website views per year

At BMC, research is always in progress.

Learn more biomedcentral.com/submissions 